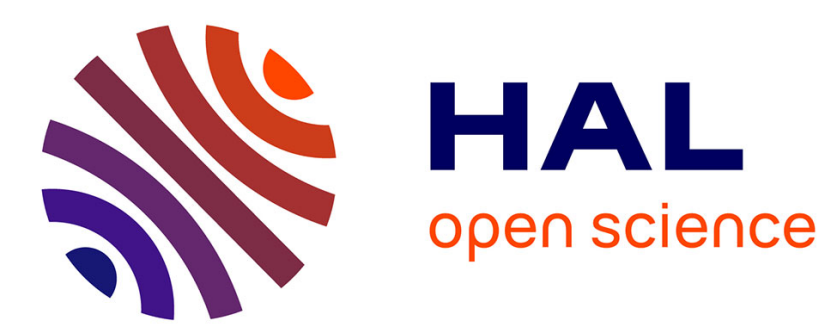

\title{
On the Solubility of Group IV Elements (Ti, Zr, Hf) in Liquid Aluminum Below $800^{\circ} \mathrm{C}$
}

\author{
Olivier Dezellus, B. Gardiola, J. Andrieux
}

\section{To cite this version:}

Olivier Dezellus, B. Gardiola, J. Andrieux. On the Solubility of Group IV Elements (Ti, Zr, Hf) in Liquid Aluminum Below $800^{\circ} \mathrm{C}$. Journal of Phase Equilibria and Diffusion, 2014, 35 (2), pp.120. 10.1007/s11669-013-0278-2 . hal-00960312

\section{HAL Id: hal-00960312 \\ https://hal.science/hal-00960312}

Submitted on 17 Mar 2014

HAL is a multi-disciplinary open access archive for the deposit and dissemination of scientific research documents, whether they are published or not. The documents may come from teaching and research institutions in France or abroad, or from public or private research centers.
L'archive ouverte pluridisciplinaire HAL, est destinée au dépôt et à la diffusion de documents scientifiques de niveau recherche, publiés ou non, émanant des établissements d'enseignement et de recherche français ou étrangers, des laboratoires publics ou privés. 


\title{
On the Solubility of Group IV Elements (Ti, $\mathrm{Zr}, \mathrm{Hf}$ ) in Liquid Aluminum Below $800^{\circ} \mathrm{C}$
}

\author{
O. Dezellus, B. Gardiola, and J. Andrieux
}

\author{
(Submitted November 28, 2013; in revised form December 19, 2013; published online January 9, 2014)
}

\begin{abstract}
The solubility of group IV transition metals $\mathrm{Ti}, \mathrm{Zr}$, and $\mathrm{Hf}$ in liquid $\mathrm{Al}$ was measured by the settling technique coupled with ICP-AES analysis after dissolution in hydrochloric acid. The kinetic aspect of the settling technique was studied in order to show that, after a cooling step, thermodynamic equilibrium between the liquid and solid phases could be achieved after only $1 \mathrm{~h}$. Finally, it was verified that solubility values obtained after a cooling or a heating step were fully consistent. The present results demonstrate that the immersion-and-settling technique allows reliable solubility values to be determined. The results confirm the values previously reported in the literature and the good description for the three binaries by the existing CALPHAD optimizations concerning the liquidus below $800^{\circ} \mathrm{C}$.
\end{abstract}

Keywords aluminum alloys, binary system, experimental techniques, liquidus

\section{Introduction}

The alloying of $\mathrm{Al}$ with group IV transition metals ( $\mathrm{Ti}$, $\mathrm{Zr}$, and $\mathrm{Hf}$ ) constitutes a promising solution for the development of creep-resistant and thermally stable Albased alloys. $^{[1]}$ A strengthening effect is obtained by precipitation of an ordered $\mathrm{Al}_{3} \mathrm{M}$ aluminide $(\mathrm{M}=\mathrm{Ti}, \mathrm{Zr}$, or Hf) from the supersaturated solid solution matrix. The temporal sequence of precipitation consists initially of the formation of metastable cubic $\mathrm{Ll}_{2} \mathrm{Al}_{3} \mathrm{M}$ precipitates which transform to their equilibrium tetragonal forms $\left(\mathrm{D}_{22}\right.$ or $\mathrm{D}_{23}$ ) after prolonged aging at temperatures above $450^{\circ} \mathrm{C}^{[2]}$ This precipitation sequence has been demonstrated for alloys prepared by non-equilibrium processing routes, such as rapid solidification techniques ${ }^{[3-6]}$ or mechanical alloying, ${ }^{[-10]}$ that allow the formation of a supersaturated $\alpha-\mathrm{Al}$ solid solution followed by the precipitation of the $\mathrm{L}_{2}$ metastable form of the aluminide. However, some difficulties arise when conventional solidification is used.

According to the accepted phase diagrams, among Al-Ti, $\mathrm{Al}-\mathrm{Zr}$, and Al-Hf systems are characterized by the presence of a peritectic transition between the $\alpha$-Al solid solution and the $\mathrm{Al}_{3} \mathrm{M}$ aluminide. ${ }^{[11-13]}$ For liquid $\mathrm{Al}$ enriched in transition metals, the first crystallization phase to form is a pro-peritectic $\mathrm{Al}_{3} \mathrm{M}$ ordered phase. During conventional casting, this primary phase nucleates and grows into coarse grains (typically $100 \mu \mathrm{m}$ ), leading to a significant decrease

O. Dezellus, B. Gardiola, and J. Andrieux, Université Claude Bernard Lyon 1, LMI - UMR CNRS N ${ }^{\circ}$ 5615, 43 Bd du 11 Novembre 1918, 69622 Villeurbanne Cedex, France. Contact e-mail: olivier.dezellus@univ-lyon1.fr. in the liquid of the transition metal. As a consequence, the final $\alpha$-Al solid solution is also depleted in solute, and this - associated with the peritectic nature of the phase diagram-limits the driving force for solid-state nucleation, i.e., the potential for age hardening. ${ }^{[14,15]}$ According to the classical nucleation theory, ${ }^{[14]}$ the ability of a peritectic alloy to be strengthened by precipitation during conventional casting is strongly related to the relative position of the liquidus and solvus lines. This results from the difficulty in obtaining a sufficient chemical driving-force (in other words supersaturation) in the solid solution at the aging temperature. As a consequence, accurate determination of liquid solubility is a key point for understanding the whole precipitation hardening process by a liquid route. The solubility of $\mathrm{Ti}$ in liquid aluminum has been extensively studied by different authors and techniques ${ }^{[16-21]}$ and the results have been recently reviewed by Schuster et al. ${ }^{[13]}$ Solubility of $\mathrm{Zr}$ in liquid $\mathrm{Al}$ was determined both by Fink et al. in $1939^{[22]}$ and Chiotti et al. in $1964 .{ }^{[23]}$ Finally, the solubility of $\mathrm{Hf}$ in liquid $\mathrm{Al}$ has been successively determined by Rath et al. ${ }^{[24]}$ and Rokhlin et al. ${ }^{[25]}$ and reviewed by Murray et al. ${ }^{[11]}$ It should be noted that a good agreement was observed between the different authors for the solubility of $\mathrm{Ti}, \mathrm{Zr}$, and $\mathrm{Hf}$ in liquid $\mathrm{Al}$.

Recently, Janghorban et al. ${ }^{[26]}$ revised the Al-rich part of the Al-Zr binary system. The authors performed a specific bidifferential thermal analysis of an Al-1wt.\% $\mathrm{Zr}$ alloy versus pure $\mathrm{Al}$ in a DSC apparatus and concluded that the transition of the binary alloy is observed at $656 \pm 2{ }^{\circ} \mathrm{C}$, i.e., 4 degrees lower than the melting temperature of pure Al. This result indicates a eutectic nature rather than the previously accepted peritectic. ${ }^{[11]}$ As a consequence, if the last invariant is eutectic, then the solubility of $\mathrm{Zr}$ in solid $\alpha$-Al has to be lower than that in the liquid phase. This would be in disagreement with the solubility values reported in the literature for the liquid ${ }^{[22,23]}$ and the solid phase. ${ }^{[22,27-29]}$ Janghorban et al. ${ }^{[26]}$ argued that solubility values obtained for the liquid phase by the immersion technique were not reliable, and usually underestimated, because of the 
formation of intermetallic compounds at the liquid-solid interface. Solid-state diffusion of the solute metal M through these compounds toward the liquid phase can then limit the kinetics of saturation of the liquid.

The aim of this work is to bring new insights in the discussion of the eutectic/peritectic nature of the transition in the Al-rich part of Al-M phase diagrams, where $\mathrm{M}=\mathrm{Ti}$, $\mathrm{Hf}, \mathrm{Zr}$. More specifically, the first objective of this study is to report reliable and unquestionable values for the solubility of $\mathrm{Zr}$ in liquid $\mathrm{Al}$ at temperatures below $800^{\circ} \mathrm{C}$. The immersion technique has been used and experimental conditions have been carefully controlled to ensure thermodynamic equilibrium between the liquid and the solid. Moreover, the kinetic aspects of the immersion technique have also been studied in the case of Al-Zr. The second objective is to propose a consistent experimental determination of the solubility of $\mathrm{Ti}, \mathrm{Zr}$, and $\mathrm{Hf}$ in liquid $\mathrm{Al}$. The crystallographic structures of the $\mathrm{Al}_{3} \mathrm{M}$ phases in the melts have been determined by single crystal XRD in order to remove ambiguities about the stability of the aluminides.

\section{Experimental Procedure}

Binary $\mathrm{Al}-\mathrm{M}(\mathrm{M}=\mathrm{Ti}, \mathrm{Zr}$, or $\mathrm{Hf})$ alloys were first prepared from pure aluminum (Alfa-Aesar 99.999\% Al) and from lumps of pure $\mathrm{M}$. Typical analyzes are shown in Table 1. For each set of experiments, a mass of about $80 \mathrm{~g}$ of these constituents was melted by radio frequency (rf) heating in an alumina crucible lined with $\mathrm{Al}_{2} \mathrm{O}_{3}$ powder. The crucible has a conical shape with the following typical inner dimensions: height is about $70 \mathrm{~mm}$, average diameter is about $30 \mathrm{~mm}$. Aluminum was melted first at about $900^{\circ} \mathrm{C}$ and Group IV elements were then added either as pure metal ( $\mathrm{Ti}$ and $\mathrm{Hf}$ ) or, in case of $\mathrm{Zr}$, in the form of the $\mathrm{Al}_{3} \mathrm{Zr}$ intermetallic compound previously synthesized by arc melting. The overall compositions of the melt prepared were $1.96 \mathrm{wt} . \%$, (1.11 at.\%), 3.44 wt.\% (1.04 at.\%), and 4.14 wt.\% (0.65 at.\%) for Ti, $\mathrm{Zr}$, and $\mathrm{Hf}$, respectively. These amounts were optimized to be in the liquid- $\mathrm{Al}_{3} \mathrm{M}$ region in the temperature range of the study and to minimize the amount of crystals in order to avoid accidental aspiration of settled crystals. The temperature was measured, with a precision better than $\pm 0.2^{\circ} \mathrm{C}$, by plunging a K-type $(\mathrm{Ni} / \mathrm{Cr})$ thermoelectric couple into the melt.

Dissolution of group IV elements and saturation of the melt was ensured by a holding time of about $2 \mathrm{~h}$ at $900^{\circ} \mathrm{C}$ and with regular stirring. The alloy was then removed from the induction coil device, placed in a radiant furnace at $800^{\circ} \mathrm{C}$ and left undisturbed for a minimum of $4 \mathrm{~h}$ at constant temperature. During this time, the undissolved crystals of the $\mathrm{Al}_{3} \mathrm{M}$ phase settled to the bottom of the crucible because of the difference in density between $\mathrm{Al}_{3} \mathrm{M}\left(3.4 \mathrm{~g} . \mathrm{cm}^{-3}\right.$ for $\mathrm{Al}_{3} \mathrm{Ti}^{[30]} 4.13 \mathrm{~g} / \mathrm{cm}^{3}$ for $\mathrm{Al}_{3} \mathrm{Zr}, 6.32 \mathrm{~g} / \mathrm{cm}^{3}$ for $\mathrm{Al}_{3} \mathrm{Hf}^{[31]}$ ) and liquid $\mathrm{Al}$ (about $2.36 \mathrm{~g} / \mathrm{cm}^{3}$ below $800^{\circ} \mathrm{C}^{[32]}$ ). After careful removal of the dross at the center of the liquid surface, samples of liquid were taken from alloy melts by aspiration through a silica tube (inner and outer diameters: 4 and $6 \mathrm{~mm}$, respectively) about $10 \mathrm{~mm}$ below the surface of the liquid-bath. To avoid metal/oxide reaction, the silica tube was previously lined with carbon black. Solidification of the melt in the carbon-lined silica tube upon aspiration was almost instantaneous, and fine-grained homogeneous rods, $10-30 \mathrm{~mm}$ in length, were obtained. The temperature was continuously monitored during liquid sampling and a decrease of a few Kelvin (3-7 K) was observed during immersion of the silica tube. As a consequence, the effective temperature of the sample was considered as the mean value during aspiration of the liquid with an uncertainty of $\pm 3 \mathrm{~K}$. The temperature of the liquid was then decreased (or increased) by a few tens of Kelvins, and the liquid left undisturbed for a minimum of $8 \mathrm{~h}$ before the next liquid sampling.

Small slices of $20-40 \mathrm{mg}$ were then cut from the ingots obtained after liquid sampling by a diamond saw and their group IV element content was determined by chemical analysis (plasma emission spectroscopy, ICP-AES) after chemical dissolution in commercially pure hydrochloric acid. The relative uncertainty on measured values is about $5 \%$. It should be noted that, while the kinetic phenomena may lead to an underestimation of solubility, another source of measurement error, associated with the liquid sampling technique, could lead to an overestimation: instead of pure liquid sampling, accidental aspiration of isothermal crystals in equilibrium with the liquid could occur. In this case, the overall chemical analysis will systematically lead to overestimated solubility values because of dissolution of both $\mathrm{Al}$ supersaturated solid solution and isothermal $\mathrm{Al}_{3} \mathrm{M}$ crystals in $\mathrm{HCl}$. This problem can be avoided by sampling at a controlled depth in the liquid-bath, thus avoiding the lower part of the crucible, where the liquid is enriched with equilibrium crystals. The extent of the zone containing $\mathrm{Al}_{3} \mathrm{M}$ crystals is evaluated after solidification by optical micrographs performed on a cross-section of the solidified ingots. The results indicate an extent lower than $8 \mathrm{~mm}$. As a consequence, from the comparison of this result with the height of the solidified ingots (about $60 \mathrm{~mm}$ ) and the depth of liquid sampling (about $10 \mathrm{~mm}$ ), it can be conclude that liquid sampling is performed at a distance higher than

Table 1 Chemical composition (in ppm) of the metallic elements used in the present study as reported in the supplier certificates of analysis

\begin{tabular}{|c|c|c|c|c|c|c|c|c|c|c|c|}
\hline Metal & Supplier & Al & $\mathrm{Ca}$ & $\mathbf{C}$ & $\mathrm{Cr}$ & $\mathrm{Cu}$ & $\mathrm{Fe}$ & $\mathbf{N i}$ & Hf & $\mathbf{S i}$ & $\mathbf{Z r}$ \\
\hline $\mathrm{Al}$ & Alfa-Aesar & Matrix & & & & 8 & 0.4 & & & & \\
\hline $\mathrm{Ti}$ & Goodfellow & 0.65 & $<0.2$ & 11 & $<0.35$ & 0.25 & 2 & 0.11 & & 0.5 & 0.75 \\
\hline $\mathrm{Zr}$ & Goodfellow & & & 250 & 200 & & 200 & & 2500 & & Matrix \\
\hline Hf & Neyco & $<15$ & & & $<15$ & $<5$ & & $<5$ & Matrix & $<2$ & $<35$ \\
\hline
\end{tabular}




\section{Author's personal copy}

$30 \mathrm{~mm}$ from the zone where settling of $\mathrm{Al}_{3} \mathrm{M}$ crystals occurs.

In the present study, in order to validate the experimental procedure (liquid sampling, $\mathrm{HCl}$ dissolution, and ICP-AES analysis) and to obtain unquestionable results, a second analysis technique was used in the case of the Ti solute. Electron probe microanalysis (EPMA) was used to perform local analyzes of the sample after a visual inspection of the microstructure to avoid the possible presence of equilibrium crystals (present in the liquid during isothermal treatment). Some slices were embedded in resin to prepare polished sections that were examined by optical microscopy (OM) and scanning electron microscopy (SEM) and were characterized by EPMA in wavelength dispersive $\mathrm{x}$-ray spectroscopy (WDS) mode. The latter analyzes were carried out using a Camebax apparatus (Cameca) under an accelerating voltage of $15 \mathrm{kV}$ and with a beam current of $11 \mathrm{nA}$ on areas of $100 \times 100 \mu \mathrm{m}^{2}$ by repeating six counts of $10 \mathrm{~s}$ on about 10-12 different areas. Analyzes were performed near the periphery of the ingots, where the quenching effect was the most effective and the microstructure was the finest on the same representative areas. The different counting rates obtained were corrected for background noise and compared with counting rates recorded under the same conditions on complex standards of $\mathrm{Al}_{3} \mathrm{Ti}$ single crystals that were present in the bottom of the solidified ingot. With this procedure, the Ti content of the samples was obtained with a typical relative uncertainty of less than $5 \% .{ }^{[33]}$

After cooling of the crucible containing the Al-M alloy, the solidified ingot was cut, embedded in resin, and polished. Micrographic analysis on cross-sections was then used to verify the presence and settling of $\mathrm{Al}_{3} \mathrm{M}$ crystals and the complete consumption of the initial pieces of Ti or Hf. A small part of the bottom of the ingots, where the crystals of solid phase had settled, was then heat treated for $48 \mathrm{~h}$ at $700^{\circ} \mathrm{C}$, quenched in water and finally dissolved in a $10 \mathrm{wt} . \%$ $\mathrm{NaOH}$ solution in order to remove the aluminum matrix and to extract some $\mathrm{Al}_{3} \mathrm{M}$ crystals, which were subsequently characterized by single crystal x-ray diffraction (XRD).

\section{Results}

\subsection{Ti solubility in Liquid AI}

Figure 1 shows the crystals present in the bottom part of the ingot in the backscattered electron mode. The most important feature is the absence of chemical contrast through the crystals, illustrating the consumption of the initial pure Ti pieces that were fully transformed into coarse $\mathrm{Al}_{3} \mathrm{Ti}$ grains (confirmed by EDS measurements) with a spheroid shape and a typical size of about $30 \mu \mathrm{m}$. This result indicates that saturation of the liquid $\mathrm{Al}$ in the $\mathrm{Ti}$ solute is not limited by a kinetic effect such as diffusion of Ti across a diffusion barrier of aluminides.

The results for Ti solubility in liquid $\mathrm{Al}$ are presented in Fig. 2 and compared both with other experimental values. ${ }^{[17,19-21]}$ Several optimization of the Al-Ti system have been performed ${ }^{[34-36]}$ that are in fairly good agreement for the description of the $\mathrm{Al}_{3} \mathrm{Ti}$ liquidus below $900^{\circ} \mathrm{C}$, as a

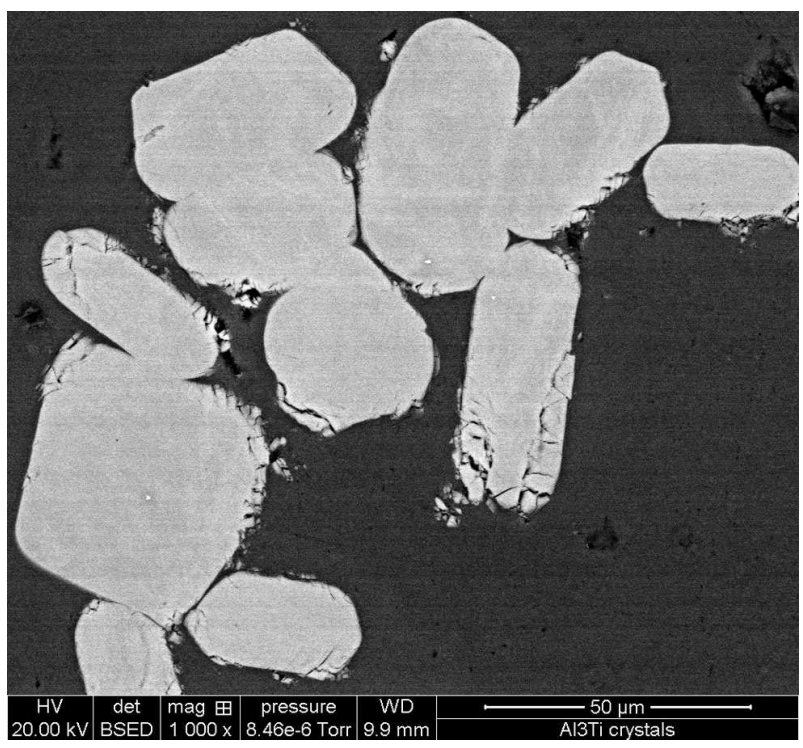

Fig. 1 SEM backscattered electron image of $\mathrm{Al}_{3} \mathrm{Ti}$ crystals observed in the bottom of the Al-Ti ingot after the complete liquid sampling process

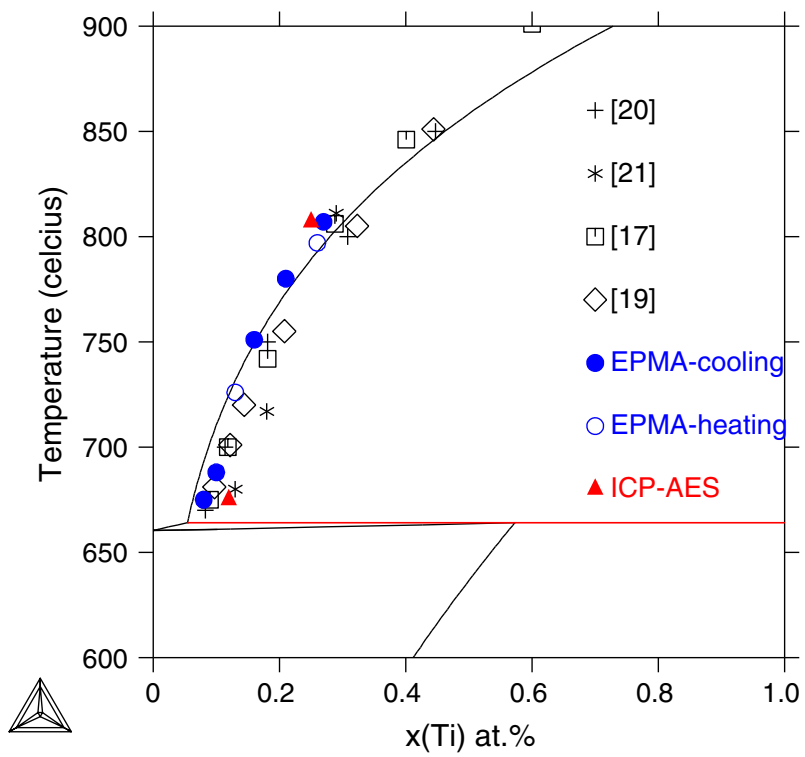

Fig. 2 Solubility limit of $\mathrm{Ti}$ in liquid $\mathrm{Al}$ determined by isothermal experiments at different temperatures and by using different analytical techniques: filled triangles are ICP-AES analysis, circles are EPMA analysis in WDS mode (the liquid sample is taken respectively during cooling - filled circles - and during heating - open circles). Experimental data are compared to previous experimental determinations ${ }^{[17,19-21]}$ and to the calculated liquidus ${ }^{[34]}$

consequence, for sake of clarity the experimental results are only compared with the liquidus calculated from the set of parameters reported in Ref 34. It is worth noting first of all that chemical analysis and WDS analysis led to a coherent 
set of solubility limit values for Ti in pure Al liquid. This quantitative agreement between a general and a local analysis technique highlights the fact that no aspiration of equilibrium crystals occurred during liquid sampling. Therefore, the solubility values reported in Fig. 2 are not overestimated. Moreover, it should be emphasized that EPMA results obtained on liquid samples both during cooling, i.e., desaturation of the liquid by precipitation of $\mathrm{Al}_{3} \mathrm{Ti}$ crystals, or during heating, i.e., saturation of the liquid by dissolution of $\mathrm{Al}_{3} \mathrm{Ti}$ crystals, are both aligned on the same liquidus curve. This convergence attests that the experimental values were obtained after thermodynamic equilibrium is reached.

In the case of Ti solute, the dissolution of the $\mathrm{Al}$ matrix in a $\mathrm{NaOH}$ solution was not sufficiently selective to allow the extraction of $\mathrm{Al}_{3} \mathrm{Ti}$ single crystals. As a consequence, it was not possible to determine by single crystal XRD the crystallographic structure of the solid phase present in the solidified ingot.

\subsection{Zr Solubility in Liquid Al}

In the case of the $\mathrm{Zr}$ solute, liquid $\mathrm{Al}$ was saturated from $\mathrm{Al}_{3} \mathrm{Zr}$ pellets synthesized using an arc furnace, a nonconsumable tungsten electrode, and a copper water-cooled hearth. In order to ensure a homogeneous composition of the pellets, the alloys were re-melted at least five times and heat treated for several hundreds of hours at $600^{\circ} \mathrm{C}$.

The results for $\mathrm{Zr}$ solubility in liquid $\mathrm{Al}$ are presented in Fig. 3 and compared both with other experimental values ${ }^{[22,23]}$ and with the most recent optimisation of Wang et al. ${ }^{[37]}$ Like Ti, the results of the present study are in good agreement with previous results given in the literature. After dissolution of the $\mathrm{Al}$ matrix in a $10 \mathrm{wt} . \% \mathrm{NaOH}$ solution, the structure of the $\mathrm{Al}_{3} \mathrm{Zr}$ aluminide was determined by single crystal XRD to be the tetragonal $\mathrm{D}_{23}$ form with lattice parameters $a=0.399 \mathrm{~nm}$ and $c=1.73 \mathrm{~nm}$ that are also in good agreement with existing literature. ${ }^{[38-41]}$

Kinetic effects at two different time scales can hinder the establishment of thermodynamic equilibrium, and thus limit the reliability of solubility results obtained by settling techniques. Firstly, when the liquid is saturated by dissolution of the pure metal, the saturation kinetics may be rate controlled by the formation of intermetallic compounds at the liquid/metal interface and solid-state diffusion through these phases. In the present case, this problem was avoided by the immersion of $\mathrm{Al}_{3} \mathrm{Zr}$ pieces in pure Al. Secondly, when the temperature was increased or decreased between two liquid sampling operations, the variation in solute content in the liquid was limited by the dissolution kinetics or precipitation of $\mathrm{Al}_{3} \mathrm{Zr}$, respectively. Therefore, in order to confirm that no kinetic effects alter the solubility values measured in the present study, a specific experiment was performed. A supersaturated ingot of $\mathrm{Al}-\mathrm{Zr}$ alloy was heated by rf coupling at $800^{\circ} \mathrm{C}$ and rapidly cooled down to $750^{\circ} \mathrm{C}$. Liquid samples were then taken at different times from 0 to $8 \mathrm{~h}$ after the temperature of $750^{\circ} \mathrm{C}$ had been reached. The chemical analyzes of the samples are presented in Fig. 4. By comparing the values with the isothermal values from Fig. 3, it is clear that, in cooling conditions, thermodynamic equilibrium was obtained after a holding time of just $1 \mathrm{~h}$. As

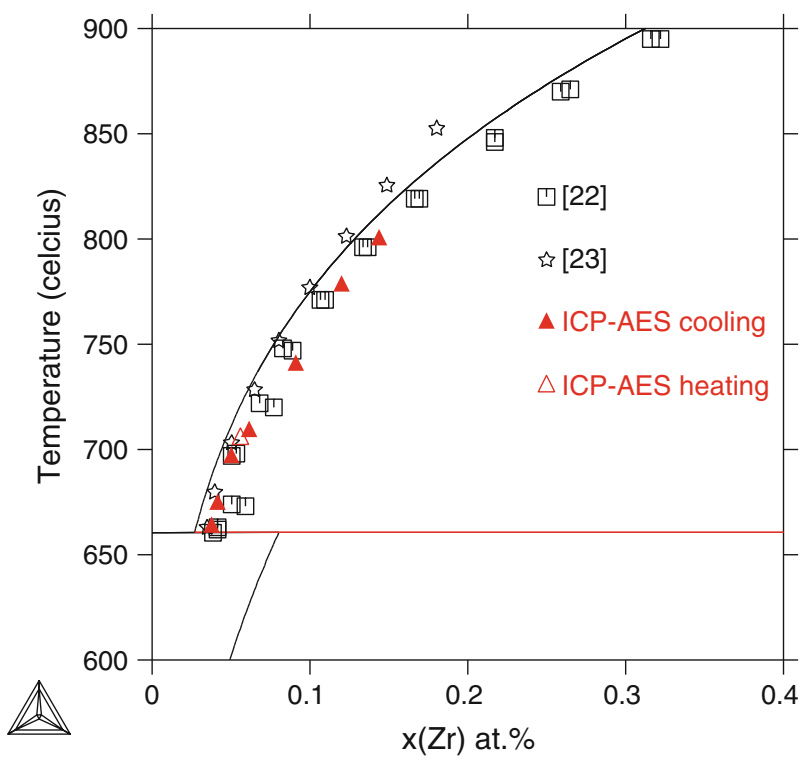

Fig. 3 Solubility limit of $\mathrm{Zr}$ in liquid $\mathrm{Al}$ determined by isothermal experiments at different temperatures by ICP-AES analysis. Liquid samples are taken respectively during cooling - filled symbols - and during heating - open symbols. Experimental data are compared to previous experimental determinations ${ }^{[22,23]}$ and to the calculated liquidus ${ }^{[37]}$

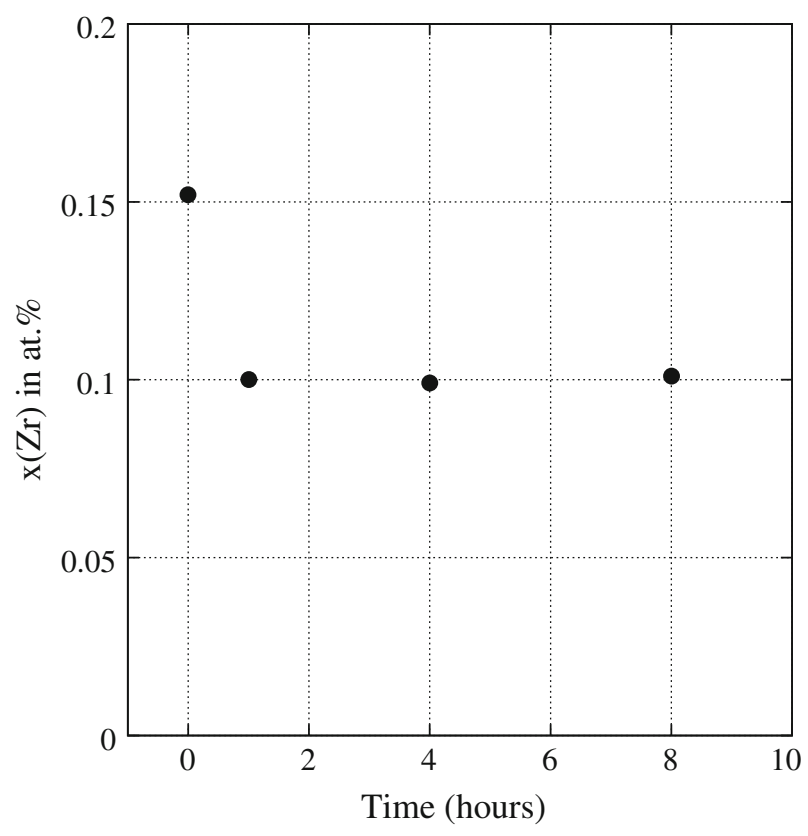

Fig. 4 Solubility of $\mathrm{Zr}$ in liquid $\mathrm{Al}$ at $750^{\circ} \mathrm{C}$, determined by ICP-AES analysis after liquid sampling as a function of time

a consequence, it can be concluded that with the holding time of 8-10 h used in the present study, no kinetic effects prevented the equilibrium conditions from being obtained. Moreover, as the three metals belong to the same group and as the Al-M binary systems are very similar, ${ }^{[11,12,42]}$ it is 


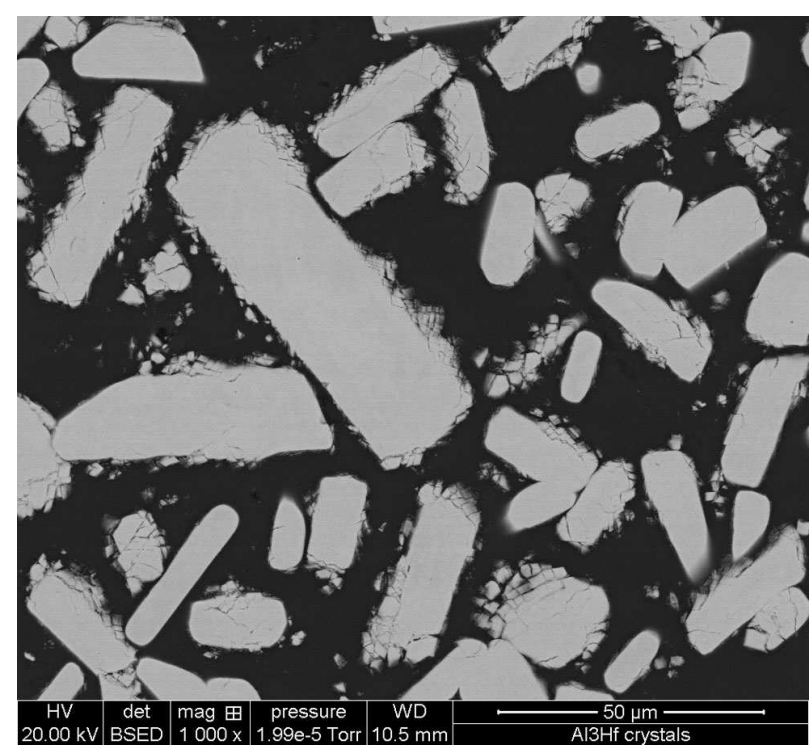

Fig. 5 SEM backscattered electron image of $\mathrm{Al}_{3} \mathrm{Hf}$ crystals observed in the bottom of the Al-Hf ingot after the full liquid sampling process

considered that this conclusion is also valid for the $\mathrm{Ti}$ and Hf solute in liquid Al.

\subsection{Hf Solubility in Liquid Al}

After solidification and cooling, the Al-Hf ingot was cut, embedded in resin and polished to confirm the formation and settling of the $\mathrm{Al}_{3} \mathrm{Hf}$ crystals and to characterize the microstructure. Figure 5 presents the resulting microstructure of the bottom part of the ingot. The absence of chemical contrast through the crystals illustrates their homogeneity and the conversion of pure $\mathrm{Hf}$ into coarse $\mathrm{Al}_{3} \mathrm{Hf}$ grains with a typical size of a few tenths of a micrometer (confirmed by EDS measurements).

Figure 6 presents the variation in Hf solubility in liquid Al below $800^{\circ} \mathrm{C}$ in comparison with experimental values reported in the existing literature ${ }^{[24,25]}$ and the optimisation of Wang et al. ${ }^{[43]}$ In the existing literature, two sets of values were reported. The results obtained in the present study are in better agreement with the largest solubility values of Rath et al. ${ }^{[2]}$, rather than with those of Rokhlin et al. ${ }^{[25]}$ It should be noticed that while Rokhlin et al. have only reported values of solubility obtained during cooling, Rath et al. reported a consistent set of values both for cooling and heating. Moreover, from the experimental details given by Rokhlin et al. ${ }^{[25]}$ it appears that the initial saturation of the liquid by $\mathrm{Hf}$ at $900^{\circ} \mathrm{C}$ is ensured by a plateau of $1 \mathrm{~h}$. Dissolution of the Hf pieces into the liquid requires a diffusion step of Hf through the hafnium aluminides that form at the liquid-Hf interface. As a consequence, if saturation of the melt from metallic pieces of $\mathrm{Hf}$ is not fulfilled after $1 \mathrm{~h}$ of plateau at $900^{\circ} \mathrm{C}$, then the liquid is not saturated, and during cooling, the measured solubilities will be smaller than the true values. In the present study, the isothermal plateau before sampling of the liquid has duration of about $6 \mathrm{~h}$ in order to limit this problem of

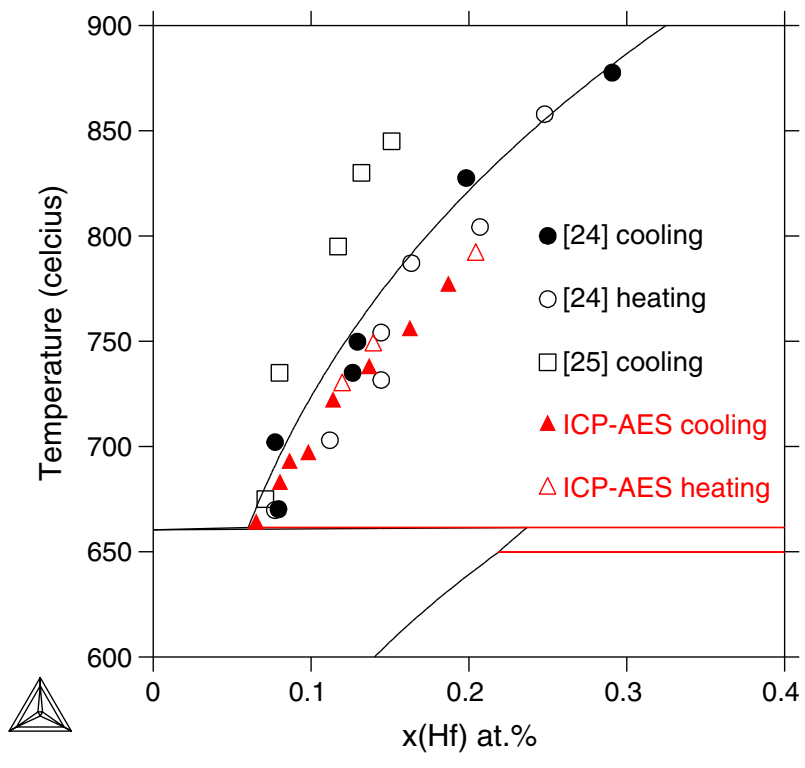

Fig. 6 Solubility limit of $\mathrm{Hf}$ in liquid $\mathrm{Al}$ determined by isothermal experiments at different temperatures by ICP-AES analysis. Liquid samples are taken respectively during cooling - filled symbols - and during heating - open symbols. Experimental data are compared to previous experimental determinations ${ }^{[24,25]}$ and to the calculated liquidus ${ }^{[43]}$ (the lowest temperature reaction correspond to the polymorphous transformation of $\mathrm{Al}_{3} \mathrm{Hf}$ from the low-temperature to the high-temperature crystal structure)

kinetics. From this discussion, it appears that the most reliable solubility values in the literature have been reported by Rath et al. ${ }^{[24]}$, and the results of the present study confirm these solubility values of $\mathrm{Hf}$ in liquid $\mathrm{Al}$ against the more recent values of Rokhlin et al. ${ }^{[25]}$

One of the arguments that can be used against the settling technique is related to the existence of a composition gradient in the liquid phase leading to non-equilibrium conditions far away from the settled crystals, where sampling is performed. Indeed saturation during heating occurs by dissolution of the settled crystals at the bottom of the crucible, while during cooling it occurs by precipitation of crystals in the liquid phase. The first process is localized and establishment of equilibrium requires a diffusion step in the liquid phase. The second one can occur everywhere in the liquid, without any diffusion step. Convergence of solubility values obtained both during cooling and heating is therefore a strong evidence of thermodynamic equilibrium.

After dissolution of the $\mathrm{Al}$ matrix in a $10 \mathrm{wt} . \% \mathrm{NaOH}$ solution, the structure of the $\mathrm{Al}_{3} \mathrm{Hf}$ aluminide was determined by single crystal XRD to be the tetragonal $\mathrm{D}_{23}$ form with lattice parameters $a=0.3983 \mathrm{~nm}$ and $c=1.7104 \mathrm{~nm}$ that are in good agreement with the existing literature. ${ }^{[12,40,44]}$

\section{Conclusion}

In the present study, the solubility of group IV transition metals $\mathrm{Ti}, \mathrm{Zr}$, and $\mathrm{Hf}$ in liquid $\mathrm{Al}$ was measured by the 
settling technique coupled with ICP-AES analysis after dissolution in hydrochloric acid. The results confirmed the values previously reported in the literature and the good description for the three binaries by the existing CALPHAD optimizations concerning the liquidus below $800^{\circ} \mathrm{C}$.

After the existing experimental liquidus of $\mathrm{Al}-\mathrm{Zr}$ was questioned by Janghorban et al. ${ }^{[26]}$, it was important to report new values with special attention being paid to their arguments, i.e., to insure and verify the establishment of thermodynamic equilibrium between the liquid and solid phases. This was achieved firstly by saturation of the liquid in $\mathrm{Zr}$ from $\mathrm{Al}_{3} \mathrm{Zr}$ crystals and not from pure $\mathrm{Zr}$. Then, no intermediate layers were formed around the solid phase; and the saturation kinetics of the melt were not limited by a solid-state diffusion process. Secondly, the kinetic aspect of the settling technique was studied in order to show that, after a cooling step, thermodynamic equilibrium between the liquid and solid phases could be achieved after only $1 \mathrm{~h}$. Finally, it was verified that solubility values obtained after a cooling or a heating step were fully consistent. The present results demonstrate that the immersion-and-settling technique allows reliable solubility values to be determined.

In addition, the crystallographic structure of the $\mathrm{Al}_{3} \mathrm{M}$ aluminide in equilibrium with the liquid was determined in the case of $\mathrm{Zr}$ and Hf. X-ray diffraction was performed on single crystals and confirmed the presence of the phase recognized as being the most stable for the Al-Zr and Al-Hf systems.

It should be noted that the liquid solubility results of the present study cannot be used to draw any conclusions concerning the nature of the last invariant in the $\mathrm{Al}-\mathrm{Zr}$ system until new and careful solid solubility limit measurements have been obtained.

\section{Acknowledgments}

The authors are grateful to the inorganic analysis team of Dr. Ayouni of the Analytical Sciences Institute for chemical analyses, "Centre Technologique des Microstructures, Université Lyon 1" for SEM and EPMA characterizations and Dr. Jeanneau from the "Centre de diffractométrie Henri Longchambon (Université Lyon1)" for the single-crystal data analyzes. The authors gratefully acknowledge the members of these organizations for their help and Marc Lomello-Tafin and Amin Janghorban for providing $\mathrm{Al}_{3} \mathrm{Zr}$ and fruitful discussions.

\section{References}

1. K.E. Knipling, D.C. Dunand, and D.N. Seidman, Criteria for Developing Castable, Creep-Resistant Aluminum-Based Alloys-A Review, Z. Metallkd., 2006, 97(3), p 246-265

2. K.E. Knipling, D.C. Dunand, and D.N. Seidman, Precipitation Evolution in Al-Zr and Al-Zr-Ti Alloys During Aging at 450$600^{\circ} \mathrm{C}$, Acta Mater., 2008, 56(6), p 1182-1195

3. M.J. Koczak, and W.E. Frazier, High Strength Powder Metallurgy Aluminum Alloys II: Proceedings, G.J. Hildeman, and M.J. Koczak, Ed., (TMS, Warrendale, PA, 1986), p 353-366
4. J.F. Nie and B.C. Muddle, Microstructure in Rapidly Solidified AlTiNi Alloys, Mater. Sci. Eng., A, 1996, 215(1-2), p 92-103

5. H. Jones and W.M. Rainforth, The Coarsening of Dispersed $\mathrm{Al}_{3} \mathrm{Ti}$ in Aluminum-Based Matrices, Metall. Mater. Trans. A, 2003, 34(2), p 419-421

6. A.L. Beresina, E.A. Segida, and G.V. Kurdyumov, Microstructure Formation in Binary Al-TM Alloys Under Nonequilibrium Solidification, J. Phys., 2009, 144, p 012096

7. W.E. Frazier and M.J. Koczak, Mechanical and Thermal Stability of Powder Metallurgy Aluminum-Titanium Alloys, Scr. Metall., 1987, 21(2), p 129-134

8. J.A. Hawk, K.R. Lawless, and H.G.F. Wilsdorf, Tensile Strength of MA Aluminum Alloys With Titanium Additions, Scr. Metall., 1989, 23(1), p 119-124

9. S.H. Wang and P.W. Kao, The Strengthening Effect of $\mathrm{Al}_{3} \mathrm{Ti}$ in High Temperature Deformation of Al-Al $\mathrm{Al}_{3}$ Ti Composites, Acta Mater., 1998, 46(8), p 2675-2682

10. I.C. Barlow, H. Jones, and W.M. Rainforth, Evolution of Microstructure and Hardening, and the Role of $\mathrm{Al}_{3} \mathrm{Ti}$ Coarsening, During Extended Thermal Treatment in Mechanically Alloyed Al-Ti-O Based Materials, Acta Mater., 2001, 49(7), p 1209-1224

11. J. Murray, A. Peruzzi, and J.P. Abriata, The Al-Zr (AluminumZirconium) System, J. Phase Equilib., 1992, 13(3), p 277-291

12. J. Murray, A.J. McAlister, and D.J. Wei, The Al-Hf (Aluminum-Hafnium) System, J. Phase Equilib., 1998, 19(4), p 376-379

13. J.C. Schuster and M. Palm, Reassessment of the Binary Aluminum-Titanium Phase Diagram, J. Phase Equilib. Diffus., 2006, 27(3), p 255-277

14. D.A. Porter, K.E. Easterling, and M. Sherif, Phase Transformations in Metals and Alloys, 3rd ed., CRC Press, Boca Raton, 2009

15. K.E. Knipling, D.C. Dunand, and D.N. Seidman, Nucleation and Precipitation Strengthening in Dilute $\mathrm{Al}-\mathrm{Ti}$ and $\mathrm{Al}-\mathrm{Zr}$ Alloys, Metall. Mater. Trans. A, 2007, 38(10), p 2552-2563

16. W. Manchot and A. Leber, Compounds and Alloys of Titanium with Aluminium, Z. Anorg. Allg. Chem., 1926, 150, p 26-34

17. W.L. Fink, H. Van, and P.M. Budge, Constitution of HighPurity Aluminum-Titanium Alloys, Am. Inst. Mining Met. Eng., 1931, 393, p 18

18. H. Bohner, Supercooling of High-Melting Intermetallic Compounds of Aluminum Alloys, Z. Metallkd., 1934, 26, p 268-271

19. M. Heckler, Solubility of Titanium in Liquid Aluminium, Aluminium (Duesseldorf), 1974, 50(6), p 405-407

20. K. Shibata, T. Sato, and G. Ohira, The Solute Distributions in Dilute Al-Ti Alloys During Unidirectional Solidification, J. Cryst. Growth, 1978, 44(4), p 435-445

21. A. Abdel-Hamid, C.H. Allibert, and F. Durand, Equilibrium Between Titanium-Aluminum $\left(\mathrm{TiAl}_{3}\right)$ and Molten Aluminum: Results From the Technique of Electromagnetic Phase Separation, Z. Metallkd., 1984, 75(6), p 455-458

22. W.L. Fink and L.A. Willey, Am. Inst. Mining Met. Eng., 1939, 1009, p 12

23. P. Chiotti and P.F. Woerner, Metal Hydride Reactions. I. Reaction of Hydrogen With Solutes in Liquid Metal Solvents, J. Less-Common Met., 1964, 7(2), p 111-119

24. B.B. Rath, G.P. Mohanty, and L.F. Mondolfo, The AluminumRich End of the Aluminum-Hafnium Equilibrium Diagram, J. Inst. Met., 1961, 89, p 248-249

25. L.L. Rokhlin, N.R. Bochvar, T.V. Dobatkina, and V.G. Leont'ev, Study of the Aluminum-Rich Part of Al-Hf Phase Diagram, Metally, 2009, 3, p 93-98 


\section{Author's personal copy}

26. A. Janghorban, A. Antoni-Zdziobek, M. Lomello-Tafin, C. Antion, T. Mazingue, and A. Pisch, Phase Equilibria in the Aluminium-Rich Side of the Al-Zr System, J. Therm. Anal. Calorim., 2013, 112, p 301-305. doi:10.1007/s10973-012$2827-z$

27. V.M. Glazov, G.P. Lazarev, and G.A. Korol'kov, The Solubility of Some Transition Metals in Aluminium, Metalloved. Term. Obrab. Met., 1959, 10, p 48-50

28. M.E. Drits, E.S. Kadaner, and V.I. Kuz'mina, Solubility of Silicon and Zirconium in Aluminium, Izv. Akad. Nauk SSSR Metal., 1968, 1, p 170-175

29. G.M. Kuznetsov, A.D. Barsukov, and M.I. Abas, Solubility of $\mathrm{Mn}, \mathrm{Cr}$, Ti and $\mathrm{Zr}$ in $\mathrm{Al}$ in the Solid State, Sov. Non-Ferrous Met. Res., 1983, 11(1), p 47-51

30. A. Raman and K. Schubert, The Constitution of Some Alloy Series Related to $\mathrm{TiAl}_{3}$. II. Investigations in Some T-Al-Si and $\mathrm{T}^{4 \ldots 6}$-In Systems, Z. Metallkd., 1965, 56(1), p 44-52

31. J. Schuster and H. Nowotny, Investigations of the TernarySystems (Zr, Hf, Nb, Ta)-Al-C and Studies, Z. Metallkd., 1980, 71(6), p 341-346

32. T. Magnusson and L. Arnberg, Density and Solidification Shrinkage of Hypoeutectic Aluminum-Silicon Alloys, Metall. Mater. Trans. A, 2001, 32(10), p 2605-2613

33. V.D. Scott and C.T. Love, Quantitative Electron-Phobe Microanalysis, 2nd ed., Prentice Hall, Upper Saddle River, 1995

34. U.R. Kattner, J.-C. Lin, and Y.A. Chang, Thermodynamic Assessment and Calculation of the Ti-Al System, Metall. Trans. A, 1992, 23(8), p 2081-2090
35. I. Ohnuma, Y. Fujita, H. Mitsui, K. Ishikawa, R. Kainuma, and K. Ishida, Phase Equilibria in the Ti-Al Binary System, Acta Mater, 2000, 48(12), p 3113-3123

36. V.T. Witusiewicz, A.A. Bondar, U. Hecht, S. Rex, and T.Y. Velikanova, The Al-B-Nb-Ti System: III. Thermodynamic Re-evaluation of the Constituent Binary System Al-Ti, J. Alloys Compd., 2008, 465(1-2), p 64-77

37. T. Wang, Z. Jin, and J.-C. Zhao, Thermodynamic Assessment of the Al-Zr Binary System, J. Phase Equilib., 2001, 22(5), p 544-551

38. Y. Ma, C. Rømming, B. Lebech, J. Gjønnes, and J. Taftø, Structure Refinement of $\mathrm{Al}_{3} \mathrm{Zr}$ Using Single-Crystal X-Ray Diffraction, Powder Neutron Diffraction and CBED, Acta Crystallogr. B, 1992, 48(1), p 11-16

39. R.J. Kematick and H.F. Franzen, Thermodynamic Study of the Zirconium-Aluminum System, J. Solid State Chem., 1984, 54(2), p 226-234

40. C. Colinet, Ab-initio Calculation of Enthalpies of Formation of Intermetallic Compounds and Enthalpies of Mixing of Solid Solutions, Intermetallics, 2003, 11(11-12), p 1095-1102

41. C. Colinet and A. Pasturel, Phase Stability and Electronic Structure in $\mathrm{ZrAl}_{3}$ Compound, J. Alloys Compd., 2001, 319 (1-2), p 154-161

42. V. Raghavan, Al-Ti (Aluminum-Titanium), J. Phase Equilib. Diffus., 2005, 26(2), p 171-172

43. T. Wang, Thermodynamic Assessment of the Al-Hf Binary System, J. Phase Equilib., 2002, 23(5), p 416-423

44. C. Colinet and A. Pasturel, Phase Stability and Electronic Structure of the $\mathrm{HfAl}_{3}$ Compound, Phys. Rev. B, 2001, 64(20), p 205102 